\title{
Microencapsulation of Probiotic Culture Beads by Using Modified Psyllium Husk
}

\author{
S.A.S. Hashmi", H.W. Deshpande, A.S. Farooqui, H.M. Syed and M.D. Sontakke \\ Department of Food Microbiology and Safety, College of Food Technology, Vasantrao Naik \\ Marathwada Krishi Vidyapeeth, Parbhani-431 402, Maharashtra, India \\ *Corresponding author
}

\section{A B S T R A C T}

\begin{tabular}{|l|}
\hline Key w or d s \\
Psyllium husk, \\
Modification, \\
Microencapsulation, \\
Probiotic beads \\
\hline Article Info \\
\hline $\begin{array}{l}\text { Accepted: } \\
\text { 07 April } 2018 \\
\text { Available Online: } \\
\text { 10 May } 2018\end{array}$ \\
\hline
\end{tabular}

Psyllium as a soluble fiber has a potential to stimulate bacterial growth in digestive system, stimulate probiotic growth in the colon, this study aimed to incorporate the modified psyllium husk (MPSH) in alginate beads containing probiotic bacteria viz., L. acidophilus and $L$. bulgaricus. Dietary fiber of modified psyllium husk waaas $79.67 \%$ and functional properties also found to be improved which was utilized for further encapsulation studies. The different formulations containing ALG-MPSH were prepared using extrusion technique and characterized in terms of size, morphology and surface properties, encapsulation efficiency (EE), viabilities in acid ( $\mathrm{pH} \mathrm{1.8,2}$ hours) and bile $(0.5 \% \mathrm{w} / \mathrm{v}, 2$ hours) conditions, and release in simulated colon $\mathrm{pH}$ conditions. Three different formulations were prepared by using sodium alginate and Modified Psyllium husk with addition of 2\% alginate and various levels of modified Psyllium husk 0.1, 0.2 and $0.3 \%$ respectively were investigated. The results revealed that the prepared spherical beads had diameter $1.65 \pm 0.05 \mathrm{~mm}$ with survival $83.2 \pm 0.7 \%$ and encapsulation efficiency $99.7 \pm 0.7 \%$ was highest achieved for $0.2 \%$ Modified Psyllium.

\section{Introduction}

Psyllium, the common name used for several members of the plant genus Plantago, is gelforming mucilage composed of a highly branched arabinoxylan. The backbone consists of xylose units, while arabinose and xylose form the side chains Psyllium has been reported as a medicinally active natural polysaccharide for the treatment of constipation, diarrhea, irritable bowel syndrome, inflammatory bowel disease ulcerative colitis, colon cancer, diabetes, and hypercholesterolemia. Moreover, psyllium as a soluble fiber has a potential to stimulate bacterial growth in digestive system, and, in some reports, it has been used as prebiotic. Prebiotics is defined by Gibson and Roberfroid as "non-digestible food ingredients that beneficially affects the host by selectively stimulating the growth and/or activity of one or a limited number of bacteria in the colon, and thus improves host health (Farzaneh et al., 2012).

Dietary fibers from Psyllium have been used extensively both as pharmacological supplements, food ingredients; in processed 
food to aid weight control, to regulation of glucose control for diabetic patients and reducing serum lipid levels in hyperlipidaemias (Baljit, 2007). Fermentation and water absorption of dietary fibre components result in several beneficial health effects. Dietary fibre intake has been associated with alleviation of constipation, regulation of lipid and glucose/insulin metabolism, and carcinogenesis.

Based on the previous studies, acid modification of psyllium husk presents a competitive potential of being applied in food industry due to its lower cost than enzymatic methods. In the present study an attempt has been made to improve the physico-chemical / functional properties of psyllium for incorporation in foods by acid treatment of the raw psyllium husk, so that it will serve as a source of dietary fiber without disturbing the nutritional and sensorial characteristics of the PSH incorporated processed food products.

Probiotic is a microorganism that provides beneficial health effects. The microorganism must exhibit several characteristics such as resistance against the gastric and intestinal juices and tolerance toward the digestive enzymes degradation.

Such challenges can be addressed by microencapsulating the probiotic bacteria within a protective matrix material.

The microencapsulation matrix functions not only as a protection against harsh gastrointestinal conditions but also increases the stability and viability of live probiotic culture at various heat/moisture conditions during processing and storage.

The consumption of products supplemented with live cells of lactic acid bacteria (LAB), in particular with their probiotic strains, is believed to benefit consumers' health due to their well-documented positive impact on the function of gastro-intestinal tract and immune system, reduction of blood cholesterol, and apparent anticancer activity (Yoon et al., 2006) Many polymeric materials can be used as a microencapsulation matrix for probiotic formulation, including alginate, starch, xanthan gum, fat, gelatin, and glycerides derivatives. Among these coating materials, alginate has been recognized as the most commonly used polymer for probiotic microencapsulation in food products, because it is non-toxic, biocompatible, low cost, and easy to apply.

Encapsulation is a mechanical or physicochemical process that traps a potentially sensitive material and provides a protective barrier between it and the external conditions.

From a microbiological point of view, microencapsulation can be defined as the process of entrapment/enclosure of microorganisms cells by means of coating them with proper hydrocolloid(s) in order to segregate the cells from the surrounding environment; in a way that results in appropriate cell release in the intestinal medium (Krasaekoopt et al., 2003; Picot and Lacroix, 2003a).

\section{Materials and Methods}

\section{Material}

\section{Raw materials}

The raw materials such as Psyllium husk were procured from the local market of Parbhani.

\section{Strains of LAB: Two LAB strains were used}

Lactobacillus acidophilus

Lactobacillus bulgaricus 


\section{Methods}

\section{Preparation of stock culture}

The pure cultures i.e. Lactobacillus bulgaricus and Lactobacillus acidophilus were cultured on MRS media slants. This was incubated at $37^{\circ} \mathrm{C}$ for 48 hours and stored at $4^{\circ} \mathrm{C}$ for further use.

\section{Preparation of starter culture}

The probiotic organisms viz. Lactobacillus bulgaricus and Lactobacillus acidophilus were individually grown in MRS broth at $37^{\circ} \mathrm{C}$ for 48hrs. The cultivated MRS broth was then centrifuged at 4,000 RPM for $10 \mathrm{~min}$ to harvest the cells. The harvested cells were washed twice with 1per cent peptone water.

\section{Acid modification of psyllium husk}

Acid modification of psyllium husk was carried out as per the method described by Xiaoyin Pei (2008) with certain changes in concentration of HCL in ethanol solvent. The solvent used for psyllium husks acid treatment was ethanol with $34 \%$ - $37 \%$ hydrochloric acid $(\mathrm{HCl})$ at the varying concentration levels of $0.65 \%(\mathrm{w} / \mathrm{v})$. The study was conducted to investigate the effect of acid concentration and psyllium to solvent ratio on physicochemical/functional properties of the acid modified psyllium samples. At reaction temperature of $37.5^{\circ} \mathrm{C}$ three different psyllium -solvent ratios (PSH: Solvent @ 1:6 (w/v), $\mathrm{g} / \mathrm{mL}$ ) were tested. Thus, $48 \mathrm{~g}$ of psyllium husk was divided into 4 groups having $16 \mathrm{~g}$ PSH each, for treatments with different concentrations levels of $0.65 \%$ (w/v) of Hydrochloric acid in Ethanol solvent. Four samples in each group were designated for psyllium to solvent ratios as mentioned earlier. After the addition of the solvent, samples were incubated for 48 hours at $37.5^{\circ} \mathrm{C}$ temperature. Afterward, samples were vacuum filtered, rinsed with $95 \%$ ethanol and $100 \%$ for 2 times each, then dried and stored. Control group was treated with $100 \%$ ethanol and followed the steps of preparation mentioned above.

\section{Microencapsulation of strains}

The microencapsulation of probiotic bacteria was performed using the extrusion technique. In this method Hydrocolloid solution was prepared by using a combination of sodium alginate at 1 and 0.8 per cent $(\mathrm{w} / \mathrm{v})$ respectively. $10 \mathrm{ml}$ of inoculum $(5 \mathrm{ml}$ each of L. acidophilus and L. bulgaricus) was mixed in $2 \mathrm{gm}$ Modified psyllium husk. Probiotic culture and modified Psyllium husk powder were mixed properly and passed through a syringe in the form of droplets into $0.3 \mathrm{M}$ calcium chloride solution. Interaction between the two solutions led to formations of beads $(2-5 \mathrm{~mm})$ and the resulting beads were then stored in 0.1per cent peptone (Karthikeyan et al., 2014).

\section{Size and morphological analysis}

The particle size of beads was assessed using optical microscopy (Dinolite, Taiwan) by Scion image analyzer software. Data were collected from 60 beads in each sample, and mean particle size was reported. The topographical properties of prepared beads were investigated by scanning electron microscopy (SEM) (Philips XL30, Holland) at an accelerating voltage of $20 \mathrm{KV}$. Prior to examination, samples were prepared on aluminum stubs and coated with gold under argon atmosphere by means of a sputter coater.

\section{Encapsulation Efficiency (EE)}

To determine the encapsulation efficiency, firstly prepared beads were mechanically disintegrated in phosphate buffer $(\mathrm{pH}=6.8)$, then the number of entrapped cells after 
adequate dilution were measured by pour plate method, and counts were expressed as number of colony forming units (CFU), and calculated as

$$
\mathrm{EE}=\left(\frac{\log 10 N}{\log 10 N 0}\right) \times{ }_{100}
$$

Where $N$ is the number of viable entrapped cells released from the beads and $N O$ is the number of free cells added to the biopolymer mixture immediately before the production procedure.

Viability of encapsulated and free $L$. acidophilus and L. bulgaricus at low pH condition

Low $\mathrm{pH}$ conditions were produced using $9 \mathrm{~g} / \mathrm{L}$ sodium chloride and $3.0 \mathrm{~g} / \mathrm{L}$ of pepsin and $\mathrm{pH}$ adjusted to 1.8 with hydrochloric acid. $100 \mathrm{mg}$ beads with entrapped bacteria or $0.1 \mathrm{~mL}$ of cell suspension were mixed in $20 \mathrm{~mL}$ of acid solution and incubated for $120 \mathrm{~min}$ at $37 \circ$ Cwith constant agitation at $50 \mathrm{rpm}$. After incubation, beads were disintegrated in phosphate buffer $(\mathrm{pH}=6.8)$, then $1.0 \mathrm{~mL}$ aliquot of the mixture removed and assayed using pour plate method. The survival $(\%)$ of the bacteria was calculated as follows:

\% Survival $=(\log \mathrm{CFU} / \mathrm{g}$ beads after 2 hours exposure to acidic condition/ log CFU/g beads initial count $) \times 100$.

Viability of encapsulated and free $L$. acidophilus and $L$. bulgaricus at high bile salt concentration

Prepared beads after 2-houracid exposure were washed with distilled water, removed, and incubated in $50 \mathrm{~mL}$ of high bile condition, containing $6.8 \mathrm{~g}$ of monobasic potassium phosphate, and $10 \mathrm{~g} / \mathrm{L}$ of pan creatine with $\mathrm{pH}$ adjusted to $6.8 \pm 0.1$ using sodium hydroxide and $0.5 \% \mathrm{w} / \mathrm{v}$ ox gall for 2 hours at $37 \circ \mathrm{C}$ with constant agitation at50 rpm. Samples were then taken, and bacterial growth was assayed using pour plate method.

Release of encapsulated cells and free $L$. acidophilus and L. bulgaricus in simulated colonic pH solution

The release of the prepared beads was examined at simulated colonic $\mathrm{pH}$ solution as described by Mandal et al., the beads were mixed with50mL of simulated colonic $\mathrm{pH}$ solution containing $0.1 \mathrm{Mmonobasic}$ potassium phosphate with $\mathrm{pH}$ adjusted to $7.4 \pm 0.1$ with sodium hydroxide and incubated for $20 \mathrm{~h}$ at $37 \circ$ Cwith constant agitation at $50 \mathrm{rpm}$. Samples were taken at different time intervals, and bacterial growth was assayed using pour plate method as described in Section 2.2.5.

\section{Statistical analysis}

Statistical testing was carried out using SPSS19. All of the experiments were performed in triplicates. Data are presented as mean \pm SD. The One-Way ANOVA test was performed to assess the difference between different beads and control groups and $P$ $<0.05$ considered as a statistically significant difference.

\section{Results and Discussion}

\section{Effect of acid modification on functional properties of psyllium}

The data pertaining to the effect of acid treatments on functional properties such as hydration capacity, oil absorption capacity and water up-taking rate of native psyllium husk were studied and obtained results are presented in Table 1.

It is revealed from the Table 1 that the hydration capacity of psyllium husk was decreased with the increased level of acid 
concentration used for treatment from $3.0 \pm$ $0.03 \mathrm{ml} / \mathrm{g}$ to $1.6 \pm 0.05 \mathrm{ml} / \mathrm{g}$. Significant decrease in hydration capacity were observed in case of PSH sample treated with $0.65 \%$ acid concentration having lowest $1.6 \pm 0.05 \mathrm{ml} / \mathrm{g}$ for 1:6 - PSH : Solvent ratio followed by 1:4 $\mathrm{PSH}$ : Solvent ratio with $1.8 \pm 0.07 \mathrm{ml} / \mathrm{g}$.

Similarly, it was found that there was a substantial decrease in the hydration capacity of PSH sample treated $0.55 \%$ acid concentration for 1:6, 1:4 and 1:2 - PSH : Solvent ratios with $2.3 \pm 0.02,2.4 \pm 0.01$ and $2.5 \pm 0.04 \mathrm{ml} / \mathrm{g}$ respectively in comparison with the raw PSH having $3.0 \pm 0.03 \mathrm{ml} / \mathrm{g}$ and Control having $2.8 \pm 0.02,2.8 \pm 0.06$ and 2.9 $\pm 0.01 \mathrm{ml} / \mathrm{g}$ respectively followed by $0.50 \%$ acid concentration with $2.6 \pm 0.05,2.6 \pm 0.08$ and $2.7 \pm 0.02 \mathrm{ml} / \mathrm{g}$ respectively. For the water absorbing capacity and swelling volume results respectively, for acid treated PSH at different acid concentrations, PSH: Solvent ratios and reaction temperatures.

Proximate composition of selected acid modified psyllium husk

It can be observed from above Table 2 that moisture content increased from 7.19 to 7.36 per cent upon acid modification. Fat content decreased after acid modification from 1.84 to 0.65 per cent while protein content decreased from 2.95 to 1.22 per cent. Similarly, ash and crude fiber decreased from 2.95 to 1.22 and 3.13 to 2.69 per cent respectively. The decrease in fat, protein, ash and crude fiber content resulted due to the partial degradation of the psyllium gel hardness because of acid modification. Further, carbohydrate content increased from 85.38 to 88.50 per cent and energy value decreased from 370 to 365 $\mathrm{Kcal} / 100 \mathrm{~g}$.

Table.1 Effect of acid modification on functional properties of psyllium

\begin{tabular}{|c|c|c|c|c|}
\hline \multirow{2}{*}{$\begin{array}{c}\text { Concentration } \\
\text { of } \mathrm{HCl} \text { in } \\
\text { Ethanol } \\
\text { (Solvent) }\end{array}$} & \multirow{2}{*}{$\begin{array}{c}\text { Psyllium } \\
\text { Husk (PSH): } \\
\text { Solvent Ratio }\end{array}$} & \multicolumn{3}{|c|}{ Functional properties } \\
\hline & & $\begin{array}{c}\text { Hydration } \\
\text { capacity } \\
(\mathrm{ml} / \mathrm{g})\end{array}$ & $\begin{array}{c}\text { Oil absorption } \\
\text { capacity } \\
(\mathrm{ml} / \mathrm{g})\end{array}$ & $\begin{array}{c}\text { Water up-taking } \\
\text { rate } \\
{[\mathrm{mg} /(\mathrm{g} \times \mathrm{min})]}\end{array}$ \\
\hline \multirow[t]{3}{*}{ Control } & $1: 2$ & $2.9 \pm 0.01$ & $0.9 \pm 0.05$ & $2.1 \pm 0.05$ \\
\hline & $1: 4$ & $2.8 \pm 0.06$ & $0.9 \pm 0.01$ & $2.0 \pm 0.03$ \\
\hline & $1: 6$ & $2.8 \pm 0.02$ & $0.8 \pm 0.07$ & $1.9 \pm 0.08$ \\
\hline \multirow[t]{3}{*}{$0.50 \%$} & $1: 2$ & $2.7 \pm 0.02$ & $0.8 \pm 0.01$ & $1.91 \pm 0.03$ \\
\hline & $1: 4$ & $2.6 \pm 0.08$ & $0.7 \pm 0.06$ & $1.88 \pm 0.02$ \\
\hline & $1: 6$ & $2.6 \pm 0.05$ & $0.6 \pm 0.03$ & $1.85 \pm 0.04$ \\
\hline \multirow[t]{3}{*}{$0.55 \%$} & $1: 2$ & $2.5 \pm 0.04$ & $0.6 \pm 0.07$ & $1.82 \pm 0.01$ \\
\hline & $1: 4$ & $2.4 \pm 0.01$ & $0.6 \pm 0.01$ & $1.78 \pm 0.03$ \\
\hline & $1: 6$ & $2.3 \pm 0.02$ & $0.5 \pm 0.08$ & $1.77 \pm 0.02$ \\
\hline \multirow[t]{3}{*}{$0.65 \%$} & $1: 2$ & $2.1 \pm 0.06$ & $0.5 \pm 0.05$ & $1.74 \pm 0.04$ \\
\hline & $1: 4$ & $1.8 \pm 0.07$ & $0.5 \pm 0.03$ & $1.71 \pm 0.06$ \\
\hline & $1: 6$ & $1.6 \pm 0.05$ & $0.5 \pm 0.01$ & $1.68 \pm 0.07$ \\
\hline \multicolumn{2}{|c|}{ Raw / Native Psyllium Husk } & $3.0 \pm 0.03$ & $1.0 \pm 0.02$ & $2.20 \pm 0.03$ \\
\hline \multicolumn{2}{|c|}{$\mathrm{SE} \pm$} & 0.3692 & 0.0243 & 0.1682 \\
\hline \multicolumn{2}{|c|}{ CD@ 5\% } & 1.1077 & 0.0731 & 0.5046 \\
\hline
\end{tabular}

* Each value is average of three determinations. 
Table.2 Effect of acid modification on proximate composition of psyllium husk

\begin{tabular}{|l|c|c|}
\hline $\begin{array}{l}\text { Particulars } \\
(\mathrm{g} / 100 \mathrm{~g})\end{array}$ & $\begin{array}{c}\text { Native Psyllium Husk } \\
\text { PSH (N) }\end{array}$ & $\begin{array}{c}\text { Modified Psyllium Husk } \\
\text { PSH (M) }\end{array}$ \\
\hline Moisture & 7.19 & 7.36 \\
\hline Fat & 1.84 & 0.65 \\
\hline Protein & 2.95 & 1.22 \\
\hline Ash & 2.62 & 2.25 \\
\hline Carbohydrate & 85.38 & 88.50 \\
\hline Crude Fiber & 3.13 & 2.69 \\
\hline a) Dietary fiber & $77.66 \pm 1.28$ & $79.67 \pm 0.89$ \\
\hline b) Arabinoxylan & $47.60 \pm 0.65$ & $48.73 \pm 0.78$ \\
\hline Energy Value & $370 \mathrm{Kcal} / 100 \mathrm{~g}$ & $365 \mathrm{Kcal} / 100 \mathrm{~g}$ \\
\hline
\end{tabular}

* Each value is average of three determinations.

Table.3 Composition of the studied formulation

\begin{tabular}{|c|c|c|}
\hline Formulation & Sodium Alginate $(\%$ w/v $)$ & $\begin{array}{c}\text { Modified Psyllium } \\
\text { Husk }(\% \mathrm{w} / \mathrm{v})\end{array}$ \\
\hline F1 & 2 & 0.1 \\
\hline F2 & 2 & 0.2 \\
\hline F3 & 2 & 0.3 \\
\hline
\end{tabular}

Table.4 Size, encapsulation efficiency, and \% survival in acid condition of prepared formulations

\begin{tabular}{|l|l|l|l|l|}
\hline Formulation & Diameter $(\mathrm{mm})(\mathrm{n}=60)$ & $\begin{array}{l}\text { Count } \\
\text { after preparation }\end{array}$ & $\begin{array}{l}\text { Encapsulation } \\
\text { efficiency }(\%)\end{array}$ & $\begin{array}{l}\% \\
\text { Survival }\end{array}$ \\
\hline F1 & $1.66 \pm 0.04$ & $9.79 \pm 0.07$ & $99.8 \pm 0.9$ & $82.3 \pm 0.2$ \\
\hline F2 & $1.65 \pm 0.05$ & $9.79 \pm 0.06$ & $99.7 \pm 0.7$ & $83.2 \pm 0.7$ \\
\hline F3 & $1.64 \pm 0.03$ & $9.76 \pm 0.05$ & $99.4 \pm 0.6$ & $86.6 \pm 0.3$ \\
\hline
\end{tabular}

Flowchart for preparation of starter culture

Stock culture

Activation of bacterial strains in MRS broth separately at $37^{\circ} \mathrm{C}$ for 48 hours

Starter culture containing desired strains

$\downarrow$

Centrifugation at 4000RPM/10min

Starter culture 


\title{
Microencapsulation of strains
}

\author{
Preparation of polymer solution \\ Addition of Probiotic culture and modified Psyllium powder \\ Extrusion of the cell- Polymer Solution into calcium chloride solution \\ $\downarrow$ \\ Capsule formation by cross linking \\ Recovery of capsule and storage in $0.1 \%$ peptone solution at $4{ }^{\circ} \mathrm{C}$
}

\section{Characterization of prepared beads}

Size, morphology, encapsulation efficiency, and surface characteristic: In the preliminary experiments, different concentrations of Sodium Alginate (0.75 to $3 \% \mathrm{w} / \mathrm{v})$ and $\mathrm{CaCl} 2$ as hardening solution ( 1 to $6 \% \mathrm{w} / \mathrm{v}$ ) were examined. According to the results of this step, it was found that uniform and spherical bead preparation by ALG concentrations less than $1 \%(\mathrm{w} / \mathrm{v})$ was quite difficult because of decreased viscosity and less ion sites for cross linkage.

Also, Sodium alginate concentrations more than $2 \%(\mathrm{w} / \mathrm{v})$ were too viscous to be extruded from the syringe. Hence, the Sodium Alginate concentrations between 1 to $2 \%$ w/v were selected. Moreover, according to our tests, $4 \% \mathrm{w} / \mathrm{v} \mathrm{CaCl} 2$ produced the best result and chosen as optimum hardening solution. In the second step of preliminary tests, the concentrations of Modified Psyllium Husk to be incorporated in Sodium Alginate beads were optimized. Addition of Modified Psyllium Husk into Sodium Alginate gel results in an increase in the viscosity and adherence of resultant gel.

Indeed, incorporation of Modified Psyllium Husk in the concentrations more than 0.1, 0.2 and $0.3 \mathrm{w} / \mathrm{v}$ to Sodium Alginate in the concentrations of $2 \% \mathrm{w} / \mathrm{v}$, respectively, yields too adherent mixtures.
Table 4 shows results for diameters and encapsulation efficiencies of different ALG and Sodium Alginate- Modified Psyllium Husk beads. As it can be seen, beads ranging from 1.65 to $1.67 \mathrm{~mm}$ for ALG and from 1.66 to $1.80 \mathrm{~mm}$ for Sodium Alginate- Modified Psyllium Husk formulations were achieved. The mean diameters of beads containing PSL were significantly higher than those without Modified Psyllium Husk $(P<0.02)$ that can be attributed to the viscosity of the resultant gel. According to the studies in this regard, an increase in the viscosity of the starter gel leads to the preparation of bigger beads by the extrusion method. Furthermore, narrow range of size distribution was observed for all prepared beads and no significant differences in size $(P>0.02)$ were observed between beads contained or not $L$. acidophilus loads.

The consumption of products supplemented with live cells of lactic acid bacteria (LAB), in particular with their probiotic strains, can benefit consumers health due to their positive impact on the function of gastro-intestinal tract and immune system. This study concluded that incorporation of modified psyllium husk (MPSH) in alginate beads containing probiotic bacteria viz., $L$. acidophilus and L. Bulgaricus. As modification psyllium husk shown high dietary fiber $79.67 \%$ and functional properties also found to be improved which can be suitable for encapsulation of probiotic culture. 


\section{References}

Askari H., Farahnaki, A., Majzoobi M and Mesbahi Gh (2008) Hydrocolloid extraction from Psyllium husk and investigation on its rheological properties.18th National Iranian food science and technology conference.

Babak Haghshenas, Yousef Nami, Minoo Haghshenas, Abolfazl Barzegari, Simin Sharifi, Dayang Radiah, Rozita Rosli, Norhafizah Abdullah (2016). Effect of addition of inulin and fenugreek on the survival of microencapsulated Enterococcus durans 39C in alginatepsyllium polymeric blends in simulated digestive system and yogurt.

Baljit S. (2007) Psyllium as therapeutic and drug delivery agent. Int. J. Pharmaceutics. 334: 1-14.

Chavarri, M., I. Maranon, R. Ares, F. C. Ibanez, F. Marzo, and M. D.C. Villaran (2010) Microencapsulation of a probiotic and prebiotic in alginatechitosan capsules improves survival in simulated gastro-intestinal conditions. International Journal of Food Microbiology, vol. 142, no. 1-2, pp. 185-189.

Ding, W.K., and N. P. Shah (2009) An improved method of microencapsulation of probiotic bacteria for their stability in acidic and bile conditions during storage. Journal of Food Science, vol. 74, no. 2, pp. M53M61.

FAO/WHO (2002) Guidelines for the evaluation of probiotics in food, Food and Agriculture Organization of United Nations and World Health Organization Working Group Report, World Health Organization, London, UK.

Farzaneh Lotfipour, Shahla Mirzaeei and Maryam Maghsoodi (2012). Preparation and Characterization of Alginate and Psyllium Beads Containing
Lactobacillus acidophilus. The Scientific World Journal Volume, Article ID 680108, 8 p.

Fischer, M.H., N. Yu, G. R. Gray, J. Ralph, L. Anderson, and J. A. Marlett (2004) "The gel-forming polysaccharide of psyllium husk (Plantago ovata Forsk)," Carbohydrate Research, vol. 339, no. 11.

Gastric and intestinal juice," Food Research International, vol. 42, no. 8, pp. 10401045.

Gibson, G.R., and M. B. Roberfroid (1995) Dietary modulation of the human colonic microbiota: introducing the concept of prebiotics. Journal of Nutrition, vol. 125, no. 6, pp. 14011412

Kailasapathy, K. (2006) Survival of free and encapsulated probiotic bacteria and their effect on the sensory properties of yoghurt. $L W T, 39,1221-1227$.

Kailasapathy, K., (2002) Microencapsulation of probiotic bacteria: technology and potential applications. Current Issues inIntestinal Microbiology, vol. 3, no. 2, pp. 39-48.

Karthikeyan N., Elango A., Kumaresan G., Gopalakrishnamurty T.R. and Raghunath B.V. (2014). Enhancement of probiotic viability in ice cream by microencapsulation. International Journal of Science, Environment and Technology. 3(1): 339-347.

Krasaekoopt, W., B. Bhandari, and H. Deeth (2004) The influence of coating materials on some properties of alginate beads and survivability of microencapsulated probiotic bacteria. International Dairy Journal, vol. 14, no. 8, pp. 737-743.

Krasaekoopt, W., Bhandari, B., and Deeth H. (2003). Evaluation of encapsulation techniques of probiotics for yoghurt. Int. Dairy J. 13, 3-13. 
Mokarram, R.R., S. A. Mortazavi, M. B. H. Najafi, and F. Shahidi, (2009) "The influence of multi stage alginate coating on survivability of potential probiotic bacteria in simulated

Picot, A., and Lacroix, C. (2003). Effect of micronization on viability and thermotolerance of probiotic freezedried cultures. Int Dairy J., 13: 455-462.

Sultana, K., G. Godward, N. Reynolds, R. Arumugaswamy, P. Peiris, and K. Kailasapathy (2000) "Encapsulation of probiotic bacteria with alginate-starch and evaluation of survival in simulated gastrointestinal conditions and in yoghurt," International Journal of Food Microbiology, vol. 62, no. 1-2, pp. 4755.

Yoon KY, Woodams EE, Hang YD (2006) Production of probiotic cabbage juice by lactic acid bacteria. Bioresource Technology; 97: 1427-1430.

Yu, L., H. Lutterodt and Z. Cheng (2009). Beneficial health properties of psyllium and approaches to improve its functionality. In: Advances in Food and Nutrition Research. Taylor, S. (ed.). 55: 193-217.

\section{How to cite this article:}

Hashmi, S.A.S., H.W. Deshpande, A.S. Farooqui, H.M. Syed and Sontakke, M.D. 2018. Microencapsulation of Probiotic Culture Beads by Using Modified Psyllium Husk. Int.J.Curr.Microbiol.App.Sci. 7(05): 392-400. doi: https://doi.org/10.20546/ijcmas.2018.705.051 